\title{
Interlayer Effect on Connection of Mild Steel ST37 and Stainless Steel 201 on Rotary Friction Welding
}

\author{
Yohanes $^{\mathrm{a},{ }^{*}}$ and Muhammad Heriansyah ${ }^{\mathrm{b}}$ \\ a) Laboratory Technology Production Mechanical Engineering Department, Universitas Riau, Indonesia \\ b) Mechanical Engineering, Universitas Riau, Indonesia
}

*Corresponding author: yohanes@ lecturer.unri.ac.id

\section{Paper History}

Received: 25-January-2021

Received in revised form: 30-February-2021

Accepted: 30-March-2021

\begin{abstract}
This study aims to analyze the joint friction welding using dissimilar metal material between mild steel ST37 and stainless steel 201 with copper interlayer. The experimental method was conducted to test the welding processes. The results of the test revealed the maximum tensile strength and a hardness test value of the interlayer variation of $0.3 \mathrm{~mm}, 0.5 \mathrm{~mm}, 1 \mathrm{~mm}$ and without an interlayer. The test was obtained the effect of the addition of an interlayer on the rotary friction welding process includes the friction phase, the forging phase and the results of welding parameters in the form of motor power, motor angular speed. The test resulted changing in specimen length that was greater without using an interlayer. The duration of welding time was greater using an interlayer than without using an interlayer. The maximum tensile test results were obtained at the $1 \mathrm{~mm}$ interlayer at $482.43 \mathrm{MPa}$. The maximum hardness test result was obtained $321.34 \mathrm{VHN}$ at the $1 \mathrm{~mm}$ interlayer.
\end{abstract}

\section{KEY WORDS: Dissimilar Metal, Interlayer, Rotary Friction} Welding.

\subsection{INTRODUCTION}

The friction welding is a type of solid state welding, which the welding process is carried out in a solid phase. Welding heat is obtained from the direct conversion of mechanical energy to thermal energy through friction. Objects do not require a source of heat from electricity or combustion. The heat generated from the process of friction between surfaces will increase the temperature of the object in the axial direction with a relatively very short distance. Joining occurs when surfaces reach a temperature below the liquid temperature. Welding occurs due to the influence of pressure on the plastic metal mixing and the diffusion mechanism [1]. In friction welding, several physical phenomena occur, such as heat changes due to friction, plastic deformation and so on. The important parameters in the friction welding process include friction time, rotational speed, and friction pressure. The parameters shown above will affect the mechanical properties of the friction weld joint [2].

In friction welding it can connect two objects of different types but can be connected optimally and not optimally, welding different materials is quite difficult because of differences in material properties that cause the welding results to be less than optimal due to differences such as crystal structure, chemical composition, point melting and mechanical properties of metals [3]. Meshram \& Reddy [4] stated that different metal joints can be performed optimally if there is a suitable element between the two metals; otherwise the use of an interlayer is required to produce the joint. For different metals, which have very different coefficients of thermal expansion, the joint may fail due to thermal fatigue during welding or after welding. This is because the internal stresses are regulated in the intermetallic zone, which tends to be very brittle.

In the case of two metals having different melting temperatures or thermal conductivity, the welding process becomes complicated because one metal melts before the other metal. There is a method that can be used to combine different metals and alloys, which is friction welding. The friction welding techniques have been developed using an interlayer and there is an increase in tensile strength in welds that use an interlayer compared to welds made without an interlayer. Nugroho et al. [5] stated that the choice of copper interlayer, because it has been widely used in the engineering field. It has advantages including: corrosion resistance, high electrical and thermal conductivity, attractive appearance, high strength and ductility, as well as ease of fabrication.

Ananthapadmanaban et al. [6] stated that the combination of different metals used in welded structures has increased rapidly and continues to increase. The joining combination between mild steel and stainless steel can be useful in applications such as steel plate for tanks where the exterior is tough and tough supported by a softer core material. 
(C) 2012 ISOMAse, All rights reserved

The rotary friction welding tool was developed by Khan, \& Alhadi [7] in the Production Technology Laboratory of Mechanical Engineering Department, Riau University. The tool was modified by Ricky [8] who was redesigning it with the development of a rotary friction welding tool using the fault tree analysis method to identify the failure of a system. Based on previous observations and research on the rotary friction welding tool, the electric motor was damaged twice due to excessive loads during the welding process due to the peak load on the electric motor when it was given forging pressure. So, it interfered with the welding process, and then a flywheel was designed to minimize damage from the motor. Several studies have been conducted regarding the effect of flywheel variations on welding results, such as in Siregar [9] to determine motor power and tensile strength of mild steel, Efriansyah [10] to determine motor power and strength. The tensile mild steel with variations in the angle of the chamfer forging by [11], which conducted tests on different materials to see the effect of the flywheel on motor power and the tensile strength of the welding results.

The parameters for rotary friction welding with the addition of a flywheel, namely using a flywheel, can extend the life of the motor because it is able to store residual energy and withstand the shock load of motor rotation. So as to produce a welding process that is faster and has an optimal tensile strength value. However, in previous research, it has not used an interlayer and did not test the hardness of the welding results. So it is necessary to test rotary friction welding on different materials between mild steel ST37 and stainless steel 201 with the addition of a copper interlayer to the rotary friction welding phase and to test the mechanical properties (tensile test and hardness test) of the welding results.

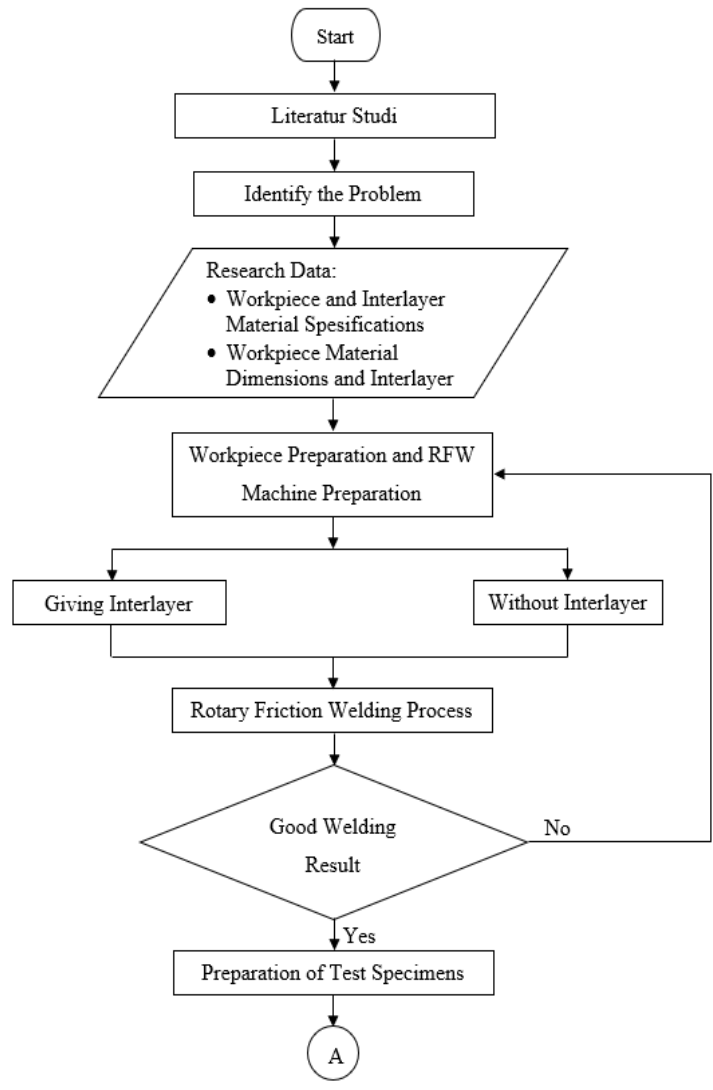

\subsection{METHOD}

\subsection{Research Method}

The research method provides an overview of the research design, which includes procedures and steps that must be taken, research time, data sources, and problem solving methods. In this paper, the research was used an experimental method. Theflow chart in this study can be seen in Figure 1.

\subsection{Making Workpieces}

The workpieces used are mild steel ST37 and stainless steel 201 with dimensions of $90 \mathrm{~mm}$ in length, $8 \mathrm{~mm}$ in diameter, and variations in interlayer thickness of $0.3 \mathrm{~mm}, 0.5 \mathrm{~mm}$, and 1 $\mathrm{mm}$ with copper material, can be seen in Figures 2-5.

This research used the materials of mild steel ST37, stainless steel 201 and interlayer copper with a chemical composition that can be seen in Table 1 .

Table 1: Chemical composition of stainless steel and mild steel

\begin{tabular}{cccccccc}
\hline Materials & \multicolumn{7}{c}{ Elements (wt. \%) } \\
\hline \multirow{2}{*}{ Mild steel } & $\mathrm{C}$ & $\mathrm{Si}$ & $\mathrm{Mn}$ & $\mathrm{Ni}$ & $\mathrm{Cr}$ & $\mathrm{Cu}$ & $\mathrm{Fe}$ \\
\cline { 2 - 8 } & 0,175 & 0,118 & 0,394 & 0,016 & 0,02 & 0,022 & 99,1 \\
\hline $\begin{array}{c}\text { Stainless } \\
\text { steel }\end{array}$ & $\mathrm{C}$ & $\mathrm{Si}$ & $\mathrm{Mn}$ & $\mathrm{Ni}$ & $\mathrm{Cr}$ & $\mathrm{Cu}$ & $\mathrm{Fe}$ \\
\cline { 2 - 8 } & 0,092 & 0,29 & 8,8 & 0,413 & 14,08 & 1,24 & 74,535 \\
\hline
\end{tabular}

Meanwhile, for testing the material after welding is using the tensile test with the ASTM-E8 standard and the hardness of the vickers with the ASTM E92-82 standard.

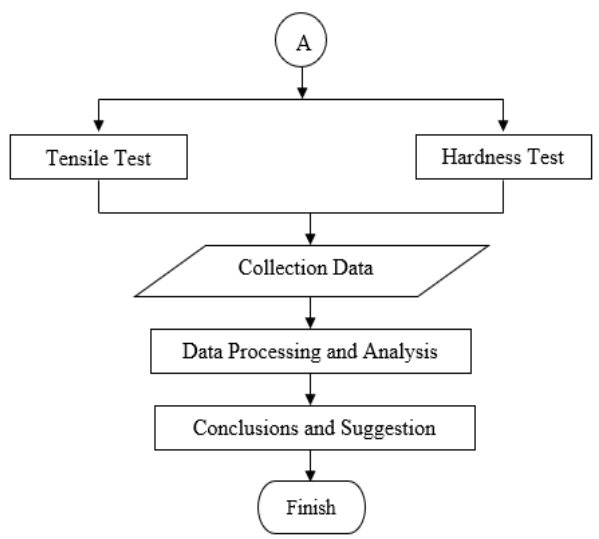

Figure 1: Research flow diagram 


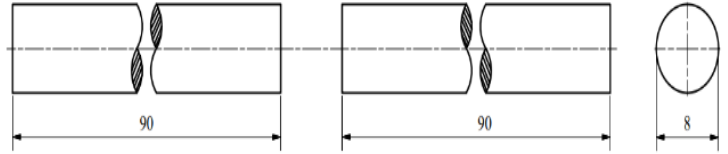

Figure 2: Material without an interlayer

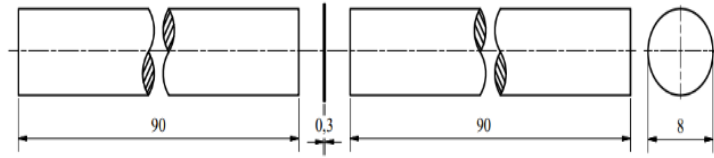

Figure 3: Material with a $0.3 \mathrm{~mm}$ interlayer

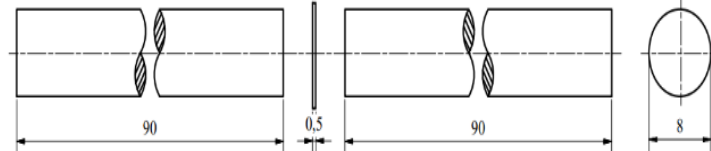

Figure 4: Material with a $0.5 \mathrm{~mm}$ interlayer

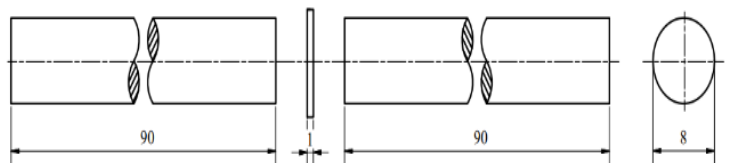

Figure 5: Material with a $1 \mathrm{~mm}$ interlayer

\subsection{Experimental Procedure}

Data collection was carried out experimentally at the Production Technology Laboratory of the Department of Mechanical Engineering, Riau University by using rotary friction welding [15] as the main tool for conducting research with $3 \mathrm{HP}$ motor specifications, 1 phase, $2800 \mathrm{rpm}$ rotation, before data collection was carried out preparation of tools and materials that could be seen in Figure 6 .

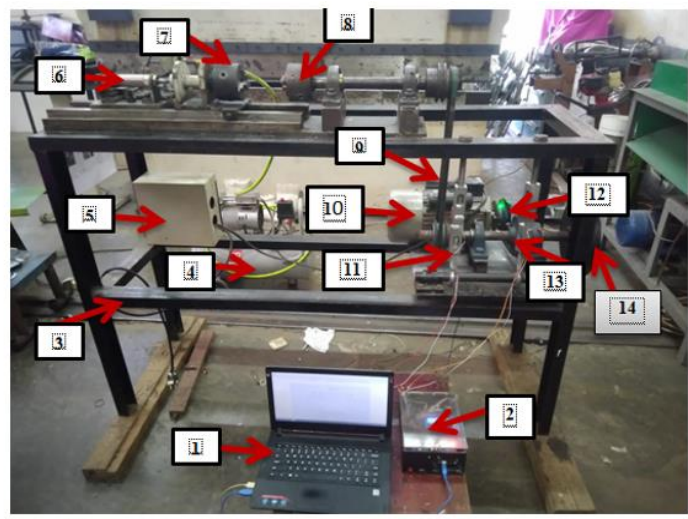

Information:
1) Laptop
8) Spinning chuck
2) Display data logger
9) Vertical v-belt
3) Rotary friction welding frame
10) Electric motor
4) Compressor
11) Stretch rod
5) Control unit
6) Pneumatic system
12) Optocoupler sensor
7) Silent chuck
13) Horizontal v-belt
14) Flywheel

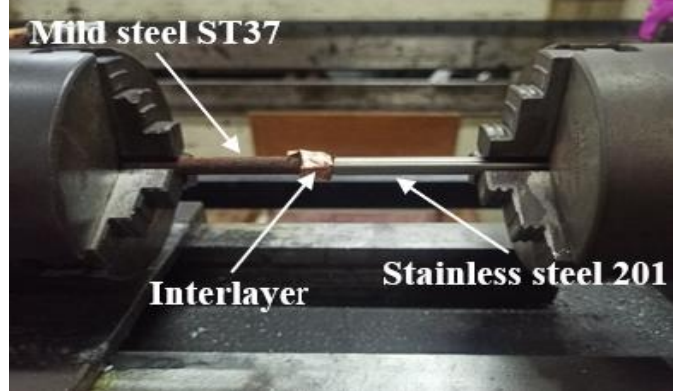

Figure 7: Laying specimens with an interlayer in rotary friction welding

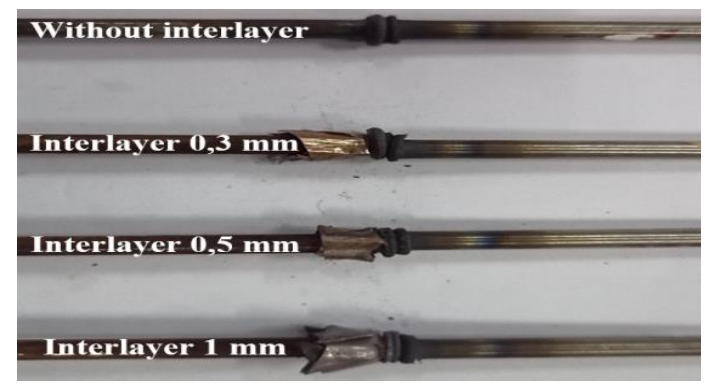

Figure 8: Rotary friction welding result test

After the preparation of the tools and materials is carried out, it is followed by the laying of the copper interlayer where the interlayer is formed to grip the workpiece with the help of pliers to facilitate the welding process so that the interlayer does not move due to vibrations from the rotary friction welding machine which can be seen in Figure 7 [12]. After welding on rotary friction welding, the results of the welding can be seen where the form of flash that occurs at the joint is almost the same in all variations of the interlayer, where the flash in mild steel is seen more than in stainless steel. This is due to the difference in the melting point of mild steel $\left(1,425^{\circ}\right.$ C) which is lower than stainless steel $\left(1,510^{\circ} \mathrm{C}\right)$. However, as the friction time increases, heat and kinetic energy increases resulting in a larger flash which can be seen in Figure 8.

\subsection{RESULT}

Based on the tests that have been carried out with variations in the thickness of the interlayer, data on the testing process, angular speed of the electric motor, power of the electric motor, tensile testing on the results of welding, and hardness testing on the results of welding are obtained.

\subsection{Test of Data}

After testing, by setting a friction pressure of 6 bars, forging pressure of 7 bars, and forging time of 5 seconds in friction welding with no interlayer and three variations of the interlayer namely $0.3 \mathrm{~mm}, 0.5 \mathrm{~mm}$, and $1 \mathrm{~mm}$, then the rotation data is obtained. friction, friction rotation time, forging rotation time, forging rotation time, flywheel stop time, change in specimen length after welding, and total welding time. Tests were carried out using one type of flywheel with variations without interlayers and inter-layers of $0.3 \mathrm{~mm}, 0.5 \mathrm{~mm}, 1 \mathrm{~mm}$. Test data can be seen in Table 2-5. 
Table 2: Experiment data without an interlayer

\begin{tabular}{|c|c|c|c|c|c|c|c|c|}
\hline \multirow{2}{*}{ Specimen } & \multicolumn{2}{|c|}{ Friction pressure } & \multicolumn{2}{|c|}{$\begin{array}{l}\text { Forging } \\
\text { pressure }\end{array}$} & \multirow{2}{*}{$\begin{array}{c}\text { Time } \\
\text { flywheel } \\
\text { stop }\end{array}$} & \multicolumn{2}{|c|}{$\begin{array}{l}\text { Spesimen } \\
\text { length }\end{array}$} & \multirow{2}{*}{$\begin{array}{l}\begin{array}{l}\text { Total } \\
\text { time }\end{array} \\
\mathrm{t}(\mathrm{s})\end{array}$} \\
\hline & $\begin{array}{c}\mathrm{n} \\
(\mathrm{rad} / \mathrm{s})\end{array}$ & $\begin{array}{l}\mathrm{t} \\
\text { (s) }\end{array}$ & $\begin{array}{c}\mathrm{n} \\
(\mathrm{rad} / \mathrm{s})\end{array}$ & $\begin{array}{c}\mathrm{t} \\
\text { (s) }\end{array}$ & & $\begin{array}{l}\text { First } \\
(\mathrm{mm})\end{array}$ & $\begin{array}{l}\text { End } \\
(\mathrm{mm})\end{array}$ & \\
\hline 1 & 323,79 & 105 & 323,88 & 5 & 6 & 180 & 175 & 116 \\
\hline 2 & 323,76 & 99 & 323,80 & 5 & 6 & 180 & 175 & 110 \\
\hline 3 & 323,85 & 94 & 323,87 & 5 & 6 & 180 & 176 & 105 \\
\hline 4 & 323,82 & 101 & 323,84 & 5 & 6 & 180 & 175 & 112 \\
\hline Average & 323,81 & 99,75 & 323,85 & 5 & 6 & 180 & 175,25 & 110,75 \\
\hline
\end{tabular}

Table 3: $0.3 \mathrm{~mm}$ interlayer experiment data

\begin{tabular}{|c|c|c|c|c|c|c|c|c|}
\hline \multirow{2}{*}{ Specimens } & \multicolumn{2}{|c|}{ Friction pressure } & \multicolumn{2}{|c|}{$\begin{array}{l}\text { Forging } \\
\text { pressure }\end{array}$} & \multirow{2}{*}{$\begin{array}{c}\text { Time } \\
\text { flywheel } \\
\text { stop } \\
t \\
(s)\end{array}$} & \multicolumn{2}{|c|}{$\begin{array}{l}\text { Spesimen } \\
\text { length }\end{array}$} & \multirow{2}{*}{$\begin{array}{l}\begin{array}{l}\text { Total } \\
\text { time }\end{array} \\
\mathrm{t}(\mathrm{s})\end{array}$} \\
\hline & $\begin{array}{c}\mathrm{n} \\
(\mathrm{rad} / \mathrm{s})\end{array}$ & $\begin{array}{l}t \\
(s)\end{array}$ & $\begin{array}{c}\mathrm{n} \\
(\mathrm{rad} / \mathrm{s})\end{array}$ & $\begin{array}{c}\mathrm{t} \\
(\mathrm{s})\end{array}$ & & $\begin{array}{l}\text { First } \\
(\mathrm{mm})\end{array}$ & $\begin{array}{l}\text { End } \\
(\mathrm{mm})\end{array}$ & \\
\hline 1 & 323,68 & 129 & 323,70 & 5 & 6 & 180 & 172 & 140 \\
\hline 2 & 323,63 & 119 & 323,65 & 5 & 6 & 180 & 17 & 130 \\
\hline 3 & 323,70 & 117 & 323,72 & 5 & 6 & 180 & 175 & 128 \\
\hline 4 & 323,68 & 121 & 323,64 & 5 & 6 & 180 & 173 & 132 \\
\hline Average & 323,67 & 121,50 & 323,68 & 5 & 6 & 180 & 173,50 & 132,50 \\
\hline
\end{tabular}

Table 4: $0.5 \mathrm{~mm}$ interlayer experiment data

\begin{tabular}{|c|c|c|c|c|c|c|c|c|}
\hline \multirow{2}{*}{ Specimens } & \multicolumn{2}{|c|}{ Friction pressure } & \multicolumn{2}{|c|}{$\begin{array}{l}\text { Forging } \\
\text { pressure }\end{array}$} & \multirow{2}{*}{$\begin{array}{c}\text { Time } \\
\text { flywheel } \\
\text { stop } \\
t \\
(\mathrm{~s})\end{array}$} & \multicolumn{2}{|c|}{$\begin{array}{l}\text { Specimen } \\
\text { length }\end{array}$} & \multirow{2}{*}{$\begin{array}{c}\begin{array}{c}\text { Total } \\
\text { time }\end{array} \\
\mathrm{t}(\mathrm{s})\end{array}$} \\
\hline & $\begin{array}{c}\mathrm{n} \\
(\mathrm{rad} / \mathrm{s})\end{array}$ & $\begin{array}{l}\mathrm{t} \\
\text { (s) }\end{array}$ & $\begin{array}{c}\mathrm{n} \\
(\mathrm{rad} / \mathrm{s})\end{array}$ & $\begin{array}{c}\mathrm{t} \\
(\mathrm{s})\end{array}$ & & $\begin{array}{l}\text { First } \\
(\mathrm{mm})\end{array}$ & $\begin{array}{l}\text { End } \\
(\mathrm{mm})\end{array}$ & \\
\hline 1 & 323,58 & 148 & 323,62 & 5 & 6 & 180 & 170 & 159 \\
\hline 2 & 323,55 & 147 & 323,58 & 5 & 6 & 180 & 17 & 158 \\
\hline 3 & 323,57 & 141 & 323,60 & 5 & 6 & 180 & 17 & 152 \\
\hline 4 & 323,62 & 144 & 323,60 & 5 & 6 & 180 & 171 & 155 \\
\hline Average & 323,58 & 145,00 & 323,60 & 5 & 6 & 180 & 171,00 & 156,00 \\
\hline
\end{tabular}

Table 5: $1 \mathrm{~mm}$ interlayer experiment data

\begin{tabular}{|c|c|c|c|c|c|c|c|c|}
\hline \multirow{2}{*}{ Specimens } & \multicolumn{2}{|c|}{ Friction pressure } & \multicolumn{2}{|c|}{$\begin{array}{l}\text { Forging } \\
\text { pressure }\end{array}$} & \multirow{2}{*}{$\begin{array}{c}\text { Time } \\
\text { flywheel } \\
\text { stop } \\
t \\
\text { (s) }\end{array}$} & \multicolumn{2}{|c|}{$\begin{array}{l}\text { Specimen } \\
\text { length }\end{array}$} & \multirow{2}{*}{$\begin{array}{c}\begin{array}{l}\text { Total } \\
\text { time }\end{array} \\
\mathrm{t}(\mathrm{s})\end{array}$} \\
\hline & $\begin{array}{c}\mathrm{n} \\
(\mathrm{rad} / \mathrm{s})\end{array}$ & $\begin{array}{l}\mathrm{t} \\
\text { (s) }\end{array}$ & $\begin{array}{c}\mathrm{n} \\
(\mathrm{rad} / \mathrm{s})\end{array}$ & $\begin{array}{c}t \\
(s)\end{array}$ & & $\begin{array}{l}\text { First } \\
(\mathrm{mm})\end{array}$ & $\begin{array}{l}\text { End } \\
(\mathrm{mm})\end{array}$ & \\
\hline 1 & 323,48 & 167 & 323,50 & 5 & 6 & 180 & 166 & 178 \\
\hline 2 & 323,46 & 171 & 323,45 & 5 & 6 & 180 & 163 & 182 \\
\hline 3 & 323,42 & 161 & 323,44 & 5 & 6 & 180 & 170 & 172 \\
\hline 4 & 323,44 & 175 & 323,45 & 5 & 6 & 180 & 162 & 186 \\
\hline Average & 323,45 & 168,50 & 323,46 & 5 & 6 & 180 & 165,25 & 179,50 \\
\hline
\end{tabular}

3.2 The Angular Velocity of the Electric Motor when Welding

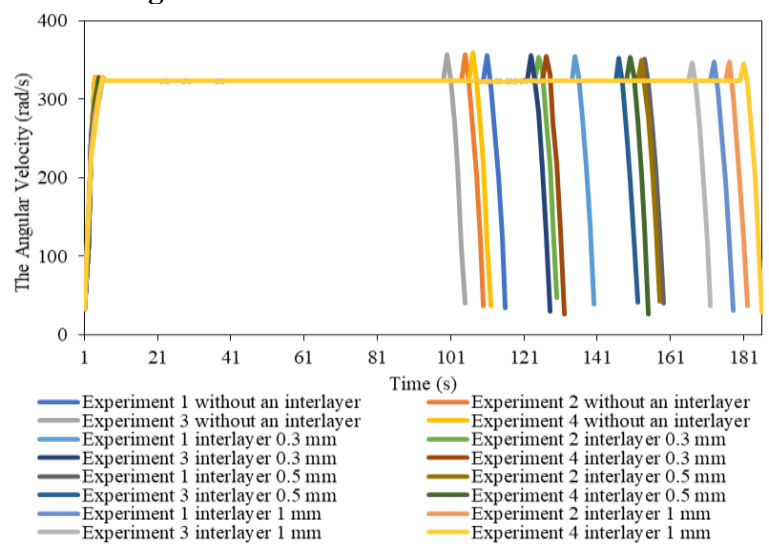

Figure 9: Graph of the angular velocity of the electric motor when welding
In Figure 9 is a graph of the angular speed of an electric motor when welding where from tests carried out without an interlayer and using an interlayer of $0.3 \mathrm{~mm}$, an interlayer of $0.5 \mathrm{~mm}$, and an interlayer of $1 \mathrm{~mm}$. The angular speed of the electric motor is obtained when welding for three stages, namely rotation initial, which the angular speed of the motor before the pressure that is applied to the specimen, which has slightly increased before experiencing constant rotation. The friction rotation is the rotation of the electric motor when the specimen subjected to 6 bars of friction pressure through pneumatics. The the forging rotation is the rotation of the electric motor when the forging process occurs. The specimen is given additional pressure to 7 bars via pneumatic.

At the angular velocity without using an interlayer, the results are stable angular velocity in the friction phase of $323.83 \mathrm{rad} / \mathrm{s}$, which is constant and the angular velocity in the forging phase is $323.85 \mathrm{rad} / \mathrm{s}$ with the required welding time varies from 116 seconds, 110 seconds, 105 seconds and 112 seconds. Whereas for the effect of the interlayer with a thickness of $1 \mathrm{~mm}$, the results of the stable angular velocity in the friction phase are $323.45 \mathrm{rad} / \mathrm{s}$, which is constant and the angular velocity in the forging phase is $323.46 \mathrm{rad} / \mathrm{s}$ with the required welding time varies from 178 seconds to 182 seconds, 172 seconds and 186 seconds.

So it can be analyzed that the effect of the thickness of the interlayer on the dissimilar metal affects the value of the angular velocity and the time of the welding process because with an interlayer thickness of $1 \mathrm{~mm}$ it takes a long time for heat input to rub against different materials. The thicker the interlayer used, the longer it takes to produce heat due to friction because it has to use up the interlayer first. As a result of the $1 \mathrm{~mm}$ interlayer thickness, the angular velocity value is small compared to other interlayer thickness variations because if the angular velocity is high it can cause the friction welding tool to experience vibrations and the material being joined is not as axis so that the interlayer layer that grips the specimen is released. This can be seen in Figure 9 which states the results of angular velocity using the thicker interlayer thickness resulting in longer time duration.

\subsection{The Persentage Error of the Angular Velocity of the Electric Motor}

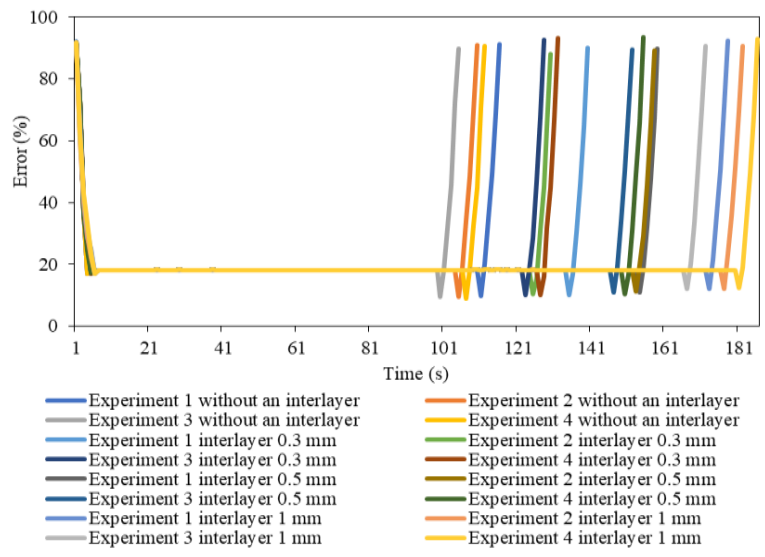

Figure 10: Graph of the percentage error of the angular velocity of the electric motor

In Figure 10 is a graph of the percentage error for the angular speed of an electric motor where the percentage error at the angular speed of an electric motor results in a stable speed. In 
the friction phase reaching a value of less than $20 \%$ is a comparison of the percentage error to the motor specifications used. So that the results of the angular speed obtained in accordance with the results of the speed on the electric motor used. All results obtained for the variation in the thickness of the interlayer are in accordance as described in Figure 7. If the effective rotational speed of the motor is used $3770.1 \mathrm{rpm}$ or $394.72 \mathrm{rad} / \mathrm{s}$, it is necessary to determine the difference in the value or percentage error of the measured rotational speed value during welding with the speed value.

The largest percentage error value measured occurred in the initial rotation in the first second with an average of $91.50 \%$, in the first second of the initial rotation, it indicates that when the motor is started, the angular speed exceeds the effective angular speed of the motor. Meanwhile, the other biggest is the last second when forging with an average of $90.96 \%$ due to the angular speed of the motor. Because the motor is turned off and only the rotation of the flywheel comes from.

\subsection{Electric Motor Power when Welding}

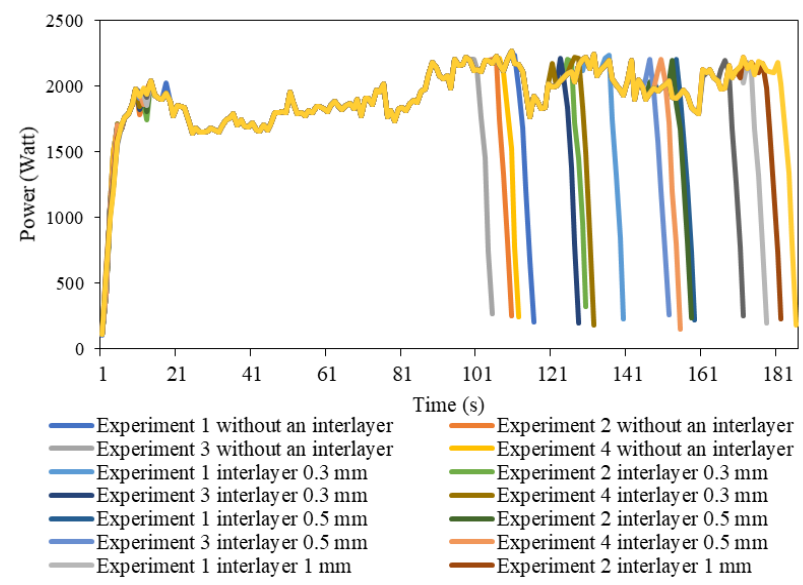

Figure 11: Graph of the electric motor power when welding

In Figure 11 is a graph of electric motor power when welding, the results of the value of the electric motor power against the duration of the welding at variations in the thickness of the interlayer, namely without using an interlayer and using an interlayer with a thickness of $0.3 \mathrm{~mm}, 0.5 \mathrm{~mm}$ and $1 \mathrm{~mm}$. It can be obtained from testing dissimilar metal specimens with variations in thickness of the interlayer for 4 experiments. The results of the power obtained different due to the application of friction pressure and the applied forging. At 6 bars of frictional pressure, the power obtained for experimental specimen 1 without using an interlayer of 2,177.21 Watt and forging pressure of 7 bars, the power value of 2218.09 Watt.

Whereas in specimens using a $1 \mathrm{~mm}$ thick interlayer with the application of friction pressure to get a power of 1985.47 Watt and giving the forging load to get a power of 2020.61 Watt. The electric motor power generated in the experiment without an interlayer is higher than using an interlayer. This is the same as the angular speed of the motor because the pressure applied slowly. So, the interlayer layer is not separated from the material to be joined. The greater the pressure applied, the greater the power required. This is directly proportional to the effect of pneumatic pressure on the power required and in accordance with the research of Sandri [11], which states that it is seen that motor power increases when given frictional pressure and increases again when given forging pressure due to increased friction that occurs due to increased pressure exerted via pneumatics.

In Figure 11, it can be seen that the power obtained varies due to differences in pressure and the required welding duration is different.

\subsection{The Persentage Error of the Electric Motor Power when Welding}

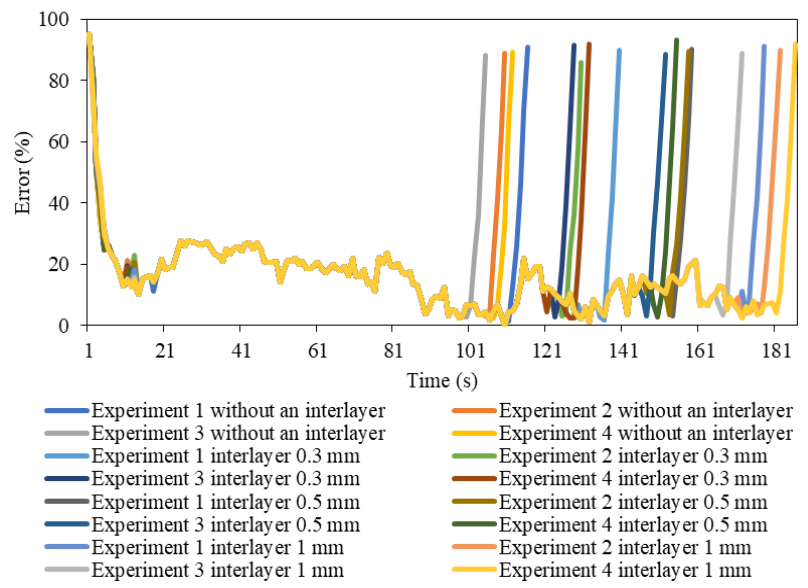

Figure 12: Graph of the percentage error of the electric motor power when welding

In Figure 12 is a graph of the percentage error in electric motor power where the percentage value of electric motor power error is obtained when welding. The effective motor power used is 3 Hp or 2237.1 Watts. The power that has been obtained is compared with the motor power specifications used. Then the average error percentage power for experimental specimen 1 without using an interlayer is $94.71 \%$ at the first second of the initial rotation and $89.21 \%$ for the power at the last second forging pressure. Whereas in specimens using $1 \mathrm{~mm}$ thick interlayer when the initial rotation of the motor gets an error percentage of $95.13 \%$ and $90.46 \%$ for the percentage error at the last second forging pressure. The percentage of error is small less than $20 \%$ obtained when the power is stable and after applying friction and forging stresses. Meanwhile, the percentage of error is large during the first second of the motor starting rotation and the last second at the forging pressure.

\subsection{Change in Specimen Length}

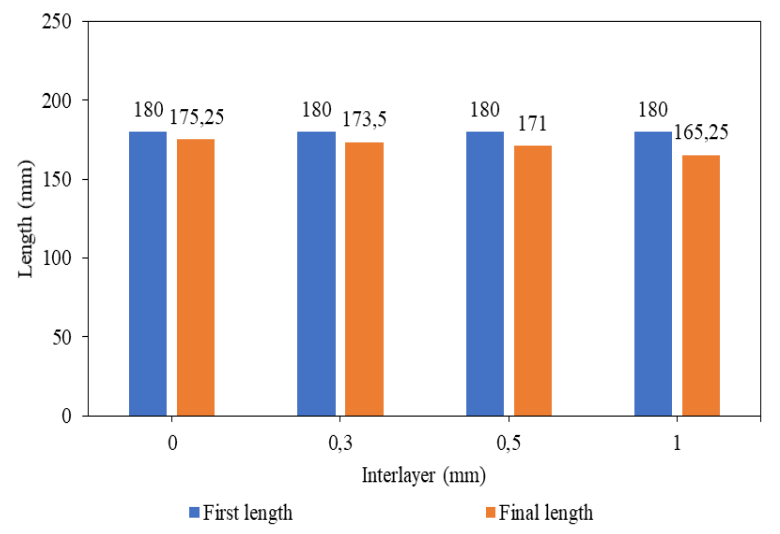

Figure 13: Graph of the average change in length of the specimen 
In Figure 13 is a graph of the average change in the length of the specimen where the graph results are obtained for the change in the length of the initial specimen to the end of the specimen during the rotary friction welding process.

The initial specimen length before welding was $180 \mathrm{~mm}$ for 4 experiments with 4 variations of the use of interlayer in the test. A changing in the final length varies due to the influence of the use of the interlayer, when the welding process lasts until the end. Variations without using an interlayer get an average final length of $175.25 \mathrm{~mm}$, whereas for using an interlayer with a thickness of 0.3 , the final length of the specimen was 173.50 $\mathrm{mm}$. When using an interlayer with an interlayer thickness of $0.5 \mathrm{~mm}$, the final specimen length is $171 \mathrm{~mm}$ and $165.25 \mathrm{~mm}$ for specimens with a $1 \mathrm{~mm}$ thick interlayer.

Based on Figure 13, it can be analyzed that the use of a thicker interlayer makes the welding specimen shorter. This is related to the welding process which takes a long time to achieve a joint. In specimens without using an interlayer, the final specimen results are longer than other variations in the thickness of the interlayer. This process is closely related to the heat generated as a result of the use of interlayer variations. The thicker the interlayer used, the greater the heat required. This is because the friction process on the friction surface of the interlayer undergoes a long melting process in terms of time which can be seen in Figure 14. Then it can be analyzed by using an interlayer which has a disadvantage, namely that the specimen becomes shorter than without using an interlayer but for the quality of the welding results it is more optimal to use interlayer which can be seen from the test results in Figures 15 and 16.

\subsection{Welding Time}

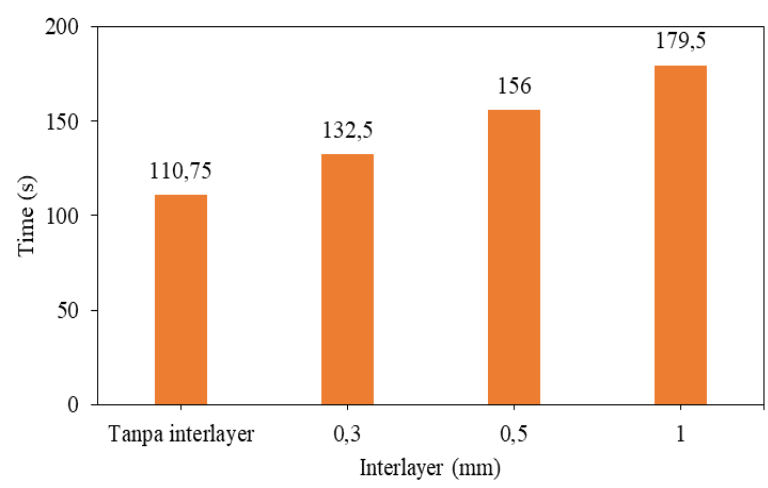

Figure 14: Graph of average welding time

Figure 14 is a graph of the average welding time where the time it takes for the specimen to weld until the specimen material is connected, the data for the welding time graph at the time of testing without an interlayer and three variations of the interlayer, namely $0.3 \mathrm{~mm}, 0.5 \mathrm{~mm}$, and $1 \mathrm{~mm}$ obtained the average time required when the welding process reaches a joint using a variation of the thickness of the interlayer. The time results obtained from using an interlayer with a thickness of 1 $\mathrm{mm}$ get a time result of 179.50 seconds, an interlayer of 0.3 $\mathrm{mm}$ is $132.50 \mathrm{~mm}$, and an interlayer of $0.5 \mathrm{~mm}$ is $156 \mathrm{~mm}$. For specimens without using an interlayer, the yield time was 110.75 seconds. So that it can be analyzed by using a variety of interlayer which are getting thicker, it will take a long time to be able to achieve a welding joint using dissimilar metal compared to without using an interlayer. This has shortcomings in welding time but is more optimal in the quality of the welding results. Time and specimen length changes are closely related and directly proportional to the welding result. It can be used a long time, which make shorter the final specimen from the welding joint. This is caused by the two surfaces of the specimen rubbing against each other against the use of the interlayer to reach the melting point so that the joint process occurs.

\subsection{Tensile Test Results}

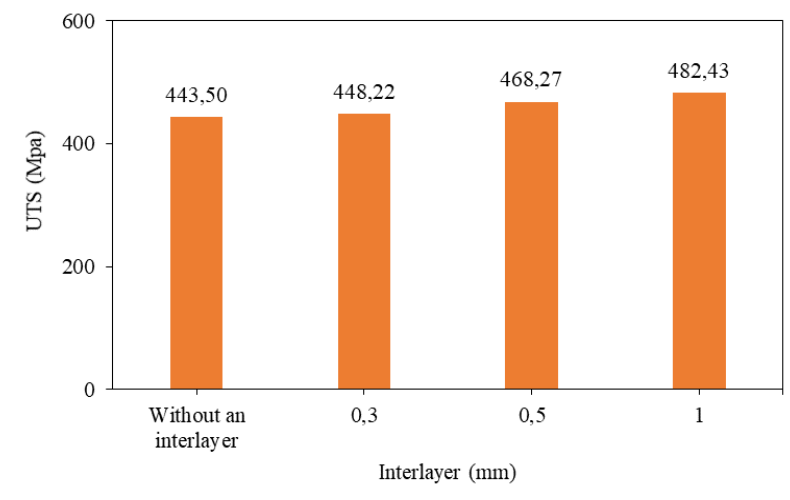

Figure 15: Graph of tensile test results

In Figure 15 is a graph of the results of the maximum tensile strength of the welding results. It is known that the average maximum tensile strength value in the variation without interlayer of $443.50 \mathrm{MPa}$. The average maximum tensile strength on the interlayer variation of $0.3 \mathrm{~mm}$ is $448.22 \mathrm{MPa}$. The average maximum tensile strength in the interlayer variation of $0.5 \mathrm{~mm}$ is $468.27 \mathrm{MPa}$, and the maximum tensile strength of the average interlayer variation of $1 \mathrm{~mm}$ that is 482.43 MPa. From the data on the average value of the maximum tensile strength in each variation of the interlayer, it is found that the highest value of the maximum tensile strength in the welding result specimen using a $1 \mathrm{~mm}$ interlayer, which has an average value of $482.43 \mathrm{MPa}$. The lowest tensile strength value is obtained in the welding specimen without using an interlayer, which has an average value of $443.50 \mathrm{MPa}$.

From Figure 15, it is known that the variation of the interlayer affects the value of the maximum tensile strength of the welding result, this is because the variation in the application of the interlayer affects the welding process which based on the research of Sathiya et al. [13] have observed fine grains in the weld metal zone when welding stainless steel. causing the welding results to be not optimal, Kumar \& Balasubramanian [14] gave a copper interlayer, which was able to increase the results of the tensile test. In addition, the copper interlayer with a smooth surface fully functions as an intermediate material between mild steel and stainless steel and is able to absorbs the grains from the stainless steel welding process and the thicker the interlayer of friction to produce the heat needed for the rotary friction welding joint process. The longer friction duration required, so that the hot working process that takes place during the welding process is. So the longer it causes the maximum tensile strength on average with $1 \mathrm{~mm}$ interlayer variation to be higher than without interlayer. Therefore, it can be analyzed that the $1 \mathrm{~mm}$ interlayer of the optimal interlayer for use in test specimens, where the $1 \mathrm{~mm}$ interlayer has the highest tensile strength value compared to other interlayer variations such as without interlayer, $0.3 \mathrm{~mm}$ interlayer, and $1 \mathrm{~mm}$ interlayer but requires longer welding time. 
In the variation without interlayer, it was found that the fracture in the area of the weld joint for the three experiments. In the interlayer variation of $0.3 \mathrm{~mm}$, it was found that the fracture was in the area of the weld joint for the three experiments. In the $0.5 \mathrm{~mm}$ interlayer variation, it was found that the fracture was in the outer area of the welded area for experiments 1 and 2, while in experiment 2 the fracture was in the area of the weld joint. In the $1 \mathrm{~mm}$ interlayer variation, it was found that the fracture was in the outer area of the weld joint for the three experiments and included the results of the maximum tensile strength value that was high than the other interlayer variations. Therefore, it can get the high quality tensile strength results.

\subsection{Hardness Test Results}

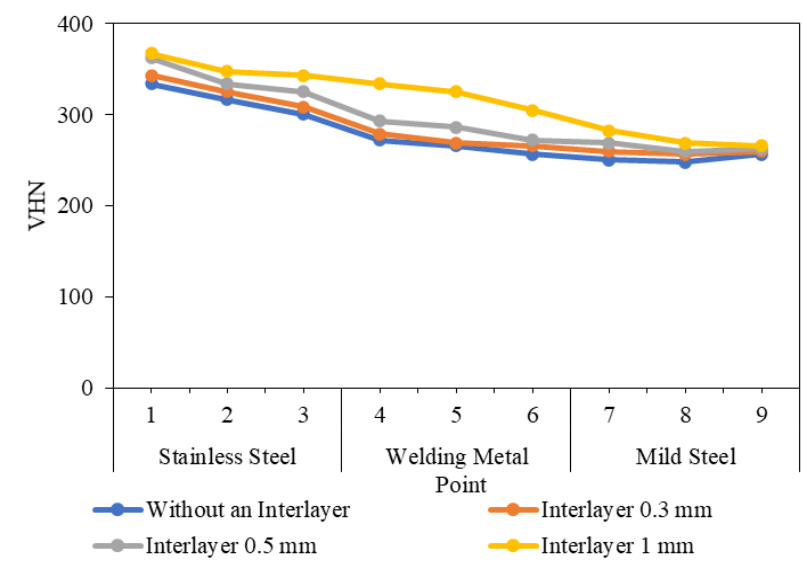

Figure 16: Graph of hardness test results

In Figure 16 is a graph of the results of hardness testing where the hardness value obtained from testing using the Vickers method. On the results of welding without an interlayer and using an interlayer of $0.3 \mathrm{~mm}, 0.5 \mathrm{~mm}, 1 \mathrm{~mm}$ with 3 indentation points on each metal area, namely on mild steel base metal ST37, main metal 201 stainless steel and welding metal with a load of $100 \mathrm{kgf}$ for 15 seconds using universal hardness testing.

It can be seen that 3 reading points were taken in each area and the average of the 3 reading points was taken for analysis. All experiments showed that the hardness values were not much or significantly different. Based on research Kumar \& Balasubramanian [14] stated that there was no major change in the base metal structure in the welding area. In stainless steel there is a decrease in hardness on the side of the weld metal. This change in the value of hardness is due to a decrease in the hardness of the joints using friction welding. Because of the stainless steel cannot be hardened by heat treatment, whereas in mild steel there is an increase in hardness at the welding interface. It is caused by the friction process that occurs during the welding process.

Figure 16 shows the relationship between the hardness of the Vickers and the test position. It can be seen where the hardness value of stainless steel decreases as the test position approaches the weld metal, while the mild steel hardness value increases as the test position approaches the weld metal. This is due to the inclusion of heat in different metals.

As it approaches the weld metal, where the highest hardness value is in the test using a $1 \mathrm{~mm}$ interlayer, namely in the weld metal area with a value of 321.34 VHN. The lowest hardness value is on the test without using an interlayer, namely in the weld metal area with a value of 264.97 VHN The difference in value is because welding using an interlayer experiences more significant heat with the help of a copper interlayer compared to welding without using an interlayer, which does not have the assistance of a copper interlayer during the welding process. This is in accordance with the research of Ananthapadmanaban et al. [6], which states that the increased hardness of the weld metal is associated with the heating of the material in the weld area. These results indicate that, hardness increases with increasing friction and welding time.

\subsection{CONCLUSION}

Based on the results of the analysis that has been carried out, it can be concluded that, the effect of adding an interlayer to the rotary friction welding process includes the friction phase, the forging phase and the results of welding parameters in the form of motor power, motor angular speed, change in the final length of the specimen and the duration of welding time. For motor power without using an interlayer, the results of the friction phase of 2177.21 Watt and forging phase of 2218.09 Watt are greater than using a $1 \mathrm{~mm}$ interlayer with a value of 1985.47 Watt friction phase and 2020.61 Watt forging phase. At the angular speed of the motor without using an interlayer, the value of the friction phase is $323.83 \mathrm{rad} / \mathrm{s}$ and the forging phase is $323.85 \mathrm{rad} / \mathrm{s}$, which is greater than using a $1 \mathrm{~mm}$ interlayer with a value of $323.45 \mathrm{rad} / \mathrm{s}$ friction phase and 323 forging phase of $46 \mathrm{rad} / \mathrm{s}$. In the change in the final length of the specimen of $4.75 \mathrm{~mm}$ from the initial length of $180 \mathrm{~mm}$ without using an interlayer is smaller than using an interlayer of $1 \mathrm{~mm}$, which is $14.75 \mathrm{~mm}$. If the welding without used an interlayer, the result is a smaller value, namely 110.75 seconds compared to using a $1 \mathrm{~mm}$ interlayer, which is 179.50 seconds. Meanwhile, the effect of the addition of the interlayer on the results of rotary friction welding is in the form of tensile test and hardness test. In the tensile strength of the friction welding joint, the maximum tensile test results obtained on the test using an interlayer of $1 \mathrm{~mm}$ with a UTS value of $482.43 \mathrm{MPa}$. Without using the interlayer get a UTS result with a low value of $443.50 \mathrm{MPa}$. In the hardness test, the highest average hardness value on the specimens resulted from welding using an interlayer of $1 \mathrm{~mm}$, namely the main metal area of stainless steel 201 has a value of $352.96 \mathrm{VHN}$. The weld metal area has a value of $321.34 \mathrm{VHN}$, and the mild steel parent area of ST37 has lowest value of $352.96 \mathrm{VHN}$. The value of $272.54 \mathrm{VHN}$ averages hardness value was obtained in the specimens of welding without using an interlayer. It is namely in the main metal area 201 stainless steel had a value of $317.23 \mathrm{VHN}$, the weld metal area had a value of $264.97 \mathrm{VHN}$, and the mild steel base metal area of ST37 has a value of $251.69 \mathrm{VHN}$.

\section{ACKNOWLEDGEMENTS}

The authors would like to convey a great appreciation to lecturers and friends in Technology Production Mechanical Engineering Department, Universitas Riau, Indonesia for supporting this research. 


\section{REFERENCES}

[1] Tiwan \& Ardian, A. (2005). Penyambungan baja aisi 1040 batang silinder pejal dengan friction welding. Laporan Penelitian. Fakultas Teknik Universitas Negeri, Yogyakarta.

[2] Prasetyono, S. \& Subiyanto, H. (2012). Pengaruh durasi gesek, tekanan gesek dan tekanan tempa terhadap impact strength sambungan lasan gesek langsung pada baja karbon AISI 1045. Jurnal Sains dan Seni Pomits. 1(1): 15 .

[3] Dawood, H.I., Mohammed, K.S. Rahmat, A. \& Uday, M. B. (2015). Microstructural characterizations and mechanical properties in friction stir welding technique of dissimilar (Al-Cu) sheets. Journal of Applied Science and Agriculture. 10(5): 149-158.

[4] Meshram, S.D. \& Reddy, G.M. (2015). Friction welding of aa6061 to aisi 4340 using silver interlayer. Defence Technology. 11(3): 292-298.

[5] Nugroho, A. W., T .Suwanda. \& S. A. Serena. 2016. Mikrostruktur dan kekerasan sambungan pengelasan gesek disimilar pipa tembaga/kuningan $(\mathrm{Cu} / \mathrm{Cu}-\mathrm{Zn})$. Jurnal Ilmah Semesta Teknika. 19(1): 68-74.

[6] Ananthapadmanaban, D., V. S. Rao., N. Abraham. \& K. P. Rao. 2009. A study of mechanical properties of friction welded mild steel to stainless steel joints. Materials and Design. 30(7): 2642-2646.

[7] Khan, M. A \& R. Alhadi. 2013. Perancangan dan Pembuatan Mesin Las Gesek Rotari. Skripsi. Program Studi Diploma Tiga Teknik Mesin Universitas Riau, Pekanbaru.

[8] Ricky \& Yohanes. 2016. Redesign Alat Las Gesek Rotari dengan Pendekatan Fault Tree Analysis (FTA) dan Design for Manufacture and Assembly (DFMA). Jom FTEKNIK. $3(2): 1-5$
[9] Yohanes, Siregar, E., Susilawati, A. \& Badri, M. (2018) Performance analysis of flywheel addition on drive system of rotary friction welding machine. Journal of Ocean, Mechanical and Aerospace-Science and Engineerin. 52(1): 14-19.

[10] Yohanes \& Efriansyah, M. (2018). Influence of flywheel for drive system of rotary friction welding and chamfer angle variations forging to welding strength. Proceeding of Ocean, Mechanical and Aerospace-Science and Engineering. 5(1)

[11] Sandri, D.V. \& Yohanes. (2018). Studi eksperimental pengaruh penambahan flywheel pada sistem penggerak mesin las gesek rotari terhadap hasil pengelasan material mild steel dengan stainless steel 201. Jom FTEKNIK. 5(2): $1-8$.

[12] Seli, H., Awang, M., Ismail, A.I.M ., Rachman, E. \& Ahmad, Z.A. (2013). Evaluation of properties and FEM model of the friction welded mild steel-Al6061-alumina. Materials Research. 16(2): 453-467.

[13] Sathiya, P., Aravindan, S. \& Haq, A.N. (2005). Mechanical and metallurgical properties of friction welded AISI 304 austenitic stainless steel. International Journal Advance Manufacturing Technology. 26: 505-511.

[14] Kumar, R. \& Balasubramanian, M. (2015). Comparative study of ti alloy and stainless steel 3041 friction welded joint with different interlayer process methods. Applied Mechanics and Materials. 766-767: 739-744.

[15] Yohanes \& Alqolbi, M.R. (2020). Development of dynamometer based on strain gauge with sensor rod type four square stalk to measuring the drive power of rotary friction welding machine. Journal of Ocean, Mechanical and Aerospace -Science And Engineering-, 64(1), 9-15. doi:10.36842/jomase.v64i1.147. 